\title{
Mucin 4 Protects Female Mice from Coronavirus Pathogenesis
}

Jessica A. Plante ${ }^{a, 1}$, Kenneth S. Plante ${ }^{b, 1}$, Lisa E. Gralinski ${ }^{a}$, Anne Beall ${ }^{a, 2}$, Martin T. Ferris ${ }^{b}$, Daniel Bottomly ${ }^{c}$, Richard Green ${ }^{d}$, Shannon K. McWeeney ${ }^{c}$, Mark T. Heise ${ }^{b, e}$, Ralph S. Baric ${ }^{a *}$, Vineet D. Menachery ${ }^{\mathrm{a}, \mathrm{f}, \star}$

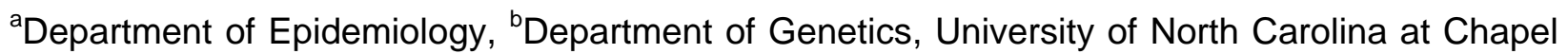
Hill, Chapel Hill, NC 27599

'Oregon Clinical and Translational Research Institute, Oregon Health \& Science University, Portland, OR 97239

${ }^{\mathrm{d}}$ Department of Immunology and the Center for Innate Immunity and Disease, University of Washington, Seattle, WA 98109

${ }^{e}$ Department of Microbiology and Immunology, University of North Carolina at Chapel Hill, Chapel Hill, NC 27599

fDeptartment of Microbiology and Immunology, University of Texas Medical Branch, Galveston, TX 77555

${ }^{*}$ Co-corresponding authors

${ }^{1}$ Current address: World Reference Center for Emerging Viruses and Arboviruses, University of Texas Medical Branch, Galveston, TX 77555

${ }^{2}$ Current address: Policy Center, J. Craig Venter Institute, La Jolla, CA 92037

Corresponding Authors: Ralph S. Baric \& Vineet D. Menachery

Address: University of North Carolina at Chapel Hill, 2107 McGavran-Greenberg Hall CB 7435, Chapel Hill, NC 27599-7435; Department of Microbiology and Immunology,301 University Blvd, Route \#0610, University of Texas Medical Branch, Galveston, TX 77555

Telephone: 919-966-7991; 409-772-9713.

Email: Rbaric@email.unc.edu; vimenach@utmb.edu

Running Title: Muc4 Protects Female Mice from CoV Pathogenesis.

Keywords: coronavirus, SARS-CoV, zoonotic, SARS-CoV-2, emergence, 2019-nCoV 


\section{Abstract}

Using incipient lines of the Collaborative Cross (CC), a murine genetic reference population, we previously identified a quantitative trait loci (QTL) associated with low SARS-CoV titer. In this study, we integrated sequence information and RNA expression of genes within the QTL to identify mucin 4 (Muc4) as a high priority candidate for controlling SARS-CoV titer in the lung. To test this hypothesis, we infected $\mathrm{Muc}^{-/-}$mice and found that female, but not male, Muc4 ${ }^{-/-}$ mice developed more weight loss and disease following infection with SARS-CoV. Female Muc4 $^{-/}$mice also had more difficulty breathing despite reduced lung pathology; however, no change in viral titers was observed. Comparing across viral families, studies with chikungunya virus, a mosquito-borne arthralgic virus, suggests that Muc4's impact on viral pathogenesis may be widespread. Although not confirming the original titer QTL, our data identifies a role for Muc4 in the SARS-CoV disease and viral pathogenesis.

\section{Importance}

Given the recent emergence of SARS-CoV-2, this work suggest that Muc4 expression plays a protective role in female mice not conserved in male mice following SARS-CoV infection. With the SARS-CoV-2 outbreak continuing, treatments that modulate or enhance Muc4 activity may provide an avenue for treatment and improved outcomes. In addition, the work highlights the importance of studying host factors including host genetics and biological sex as key parameters influencing infection and disease outcomes. 


\section{Introduction}

Most viral infections present with an array of symptoms following human infection, ranging from asymptomatic to self-limiting, chronic, and sometimes fatal disease. Some of this diversity is mediated by age, sex, and other comorbidities, but these demographics do not account for all of the variability in disease outcomes. Genome-wide association studies (GWAS) and candidate gene studies have established a number of genes associated with human susceptibility to infectious diseases, but are limited by the large populations required to detect genetic effects and by existing knowledge gaps (Fellay et al., 2007; Ge et al., 2009; Lindesmith et al., 2003; López et al., 2010). Furthermore, during outbreak settings there is often limited access to clinical samples from infected humans. Thus, host susceptibility allele identification is oftentimes heavily compromised by situational expediency and new approaches are needed to identify alleles that regulate emerging virus pathogenesis.

Severe acute respiratory syndrome virus (SARS-CoV) is a respiratory pathogen that first emerged in the Guangdong Province of China in November 2002, and rapidly spread to 28 countries, resulting in over 8,000 cases with a $10 \%$ case fatality ratio. The subsequent emergence of Middle East respiratory syndrome coronavirus (MERS-CoV) and the discovery of several other related "pre-epidemic" bat coronaviruses that seem poised for sudden emergence emphasize the need for a comprehensive understanding of how highly pathogenic human coronaviruses, such as SARS-CoV, interact with their hosts to regulate disease severity (Coleman and Frieman, 2013; Menachery et al., 2015b; Menachery et al., 2016). The importance of these early predictions was demonstrated by the ongoing outbreak of SARS-CoV2 (Gorbalenya et al., 2020; Gralinski and Menachery, 2020), which has caused 45,171 confirmed cases and 1,115 deaths as of February 12, 2020 (World Health Organization, 2020). We have developed a model of CoV infection in the genetically diverse Collaborative Cross (CC) population (Churchill et al., 2004; Collaborative Cross Consortium, 2012). This model allows us to assess the impact of host genetic variation on CoV disease, such as in the 
context of SARS-CoV pathogenesis (Gralinski et al., 2015). The CC panel contains mouse lines derived from a funnel breeding scheme of eight founder strains, including 5 traditional lab strains and 3 wild-derived strains (Churchill et al., 2004; Collaborative Cross Consortium, 2012; UNC Systems Genetics Core Facility, 2012). This population takes advantage of naturallyoccurring genetic polymorphisms to capture approximately $90 \%$ of the common genetic diversity within Mus musculus, and that diversity is distributed evenly throughout the genome, with elevated minor allele frequencies compared to standard natural populations (Aylor et al., 2011; Yang et al., 2007; Yang et al., 2009; Yang et al., 2011). Our initial screen within an incompletely inbred set of CC mice (the preCC screen) (Gralinski et al., 2015), along with an F2 screen utilizing a highly resistant and highly susceptible CC mouse line (Gralinski et al., 2017), identified nine quantitative trait loci (QTLs) impacting SARS-CoV disease. Among these QTLs was locus HrS2 on chromosome 16, which was identified as modulating SARS-CoV titer levels in the lung (Gralinski et al., 2015).

Here, we narrow the HrS2 locus to a priority candidate gene, mucin 4 (Muc4), via the integration of sequence data from the CC founders (Keane et al., 2011) and RNA expression results from our preCC experiment. Low expression of Muc4 in mice containing the PWK/PhJ allele corresponded with the low SARS-CoV titer associated with the QTL located at locus HrS2. We subsequently examined infection of mice lacking Muc4, predicting reduced viral load. However, our findings suggest that while Muc4 does not regulate SARS-CoV titer, it does have broad activity attenuating the pathogenic impact of viral infections.

\section{Results}

\section{Selection of Muc4 as a SARS-CoV disease associated gene}

In earlier studies, incipient CC lines were used to identify four QTLs associated with SARS-CoV phenotypes in female mice, one of which was mapped on the basis viral titer in the lung at four DPI (Gralinski et al., 2015). A subsequent study utilizing both male and female F2 
52 mice derived from a highly susceptible and highly resistant CC mouse line identified five more SARS-CoV-associated QTLs, three of which were mapped at least partially on the basis of viral

54 titer (Gralinski et al., 2017). Located on chromosome 16 from nucleotides 31,583,769$36,719,997$, the pre-CC QTL accounted for $22 \%$ of the variation in viral titer, which ranged from over $10^{8} \mathrm{PFU} /$ lobe to below the limit of detection $\left(10^{2} \mathrm{PFU} / \mathrm{lobe}\right)$. The F2 QTLs, by comparison, were located on chromosomes 18, 7, and 12 and explained $12.9 \%, 12.3 \%$, and $5.4 \%$, respectively, of the observed variation in titers from high $10^{2}$ to low $10^{7} \mathrm{PFU} /$ lobe. Thus, while SARS-CoV titer in the lung is clearly influenced by multiple host genetic factors, the preCC QTL on chromosome 16 was chosen for candidate gene selection and validation. Analysis of allele effects revealed that the founder PWK/PhJ was the main driver of low SARS-CoV titer in the lung (Fig. 1A), and PWK/PhJ also had lower titers than any other founder strain at four DPI (Gralinski et al., 2015). We therefore used private SNPs or In/Dels found in PWK/PhJ to reduce the potential targets in the QTL to seven ncRNAs and 74 genes for downstream analysis.

To prioritize the list of ncRNAs and genes within the QTL, the relationship between RNA transcript levels and viral titer in the lung was examined. Sixty seven preCC mice had both microarray and titer data available, of which sixty had titers above the limit of detection (Gralinski et al., 2015). Of the 74 candidate genes, 54 had one or more probes on the microarray (Table S4) and Muc4 expression had the strongest correlation with viral titer, with five of the six Muc4 probes yielding positive correlations of $0.34-0.45$ (Fig. 1B, Table S5). Using infection data from the founder mice, Muc4 RNA expression levels mimicked the allelic effects

72 of the QTL with PWK/PhJ mice exhibiting low Muc4 RNA levels (Fig. 1C). Other potential 73 targets included Lrrc33, Sec22a, Parp14, and Ildr1; however, these genes either have little 74 known linkage to viral replication and the immune response (e.g., Lrrc33, Sec22a, and Ildr1) or 75 the directionality of the correlation did not support their relationship to viral titer in the lung 76 (Parp14). For Muc4, high levels of expression at mucosal surfaces and in various human 
cancers have been reported (Andrianifahanana et al., 2001; Chaturvedi et al., 2008; Kamikawa et al., 2015). In addition, Muc4 plays a role in cell and anti-apoptotic signaling (Chaturvedi et al., 2008; Funes et al., 2006; Moniaux et al., 2007). Together, the data suggest that Muc4 may play a role in viral titers at day 4 post SARS-CoV infection.

\section{Muc4 drives sex-based difference in weight loss}

To examine the role of Muc4 during SARS-CoV infection, we utilized Muc4 ${ }^{-/}$mice (Rowson-Hodel et al., 2018) which have no gross differences in behavior, overall health, size, or lung function, the latter phenotype measured by plethysmography. Muc4 ${ }^{-/}$and WT control mice were infected with SARS-CoV and examined over a four-day time course. Following infection, a significant sex-based difference in weight loss between $\mathrm{Muc4}^{-/}$and WT mice was observed (Table S3). Female $\mathrm{Muc4}^{-/}$and control were essentially indistinguishable through two DPI (Fig. 2A). However, infected $M u c 4^{-/}$females continued to lose weight through day four, with $42 \%$ (6 of 14 ) meeting euthanasia requirements ( $\geq 20 \%$ weight loss) and another $42 \%$ (6 of 14 ) requiring increased observation ( $\geq 10 \%$ weight loss). In contrast, the WT mice held static between days two and three and began to recover by day four, with no mice meeting the requirements for euthanasia and only $13 \%$ (2 of 15 ) requiring increased observation by a margin of $\leq 0.1 \mathrm{~g}$. This Muc4-driven difference in weight loss was not observed in male mice following infection with SARS-CoV (Fig. 2B).

\section{Muc4 has minimal impact on viral load}

Next, the impact of $\mathrm{Muc4}^{-/}$on SARS-CoV viral load was measured. Lung lobes from male and female $\mathrm{Muc4}^{-1-}$ and WT mice were harvested at two DPI, an acute timepoint previously associated with high SARS-CoV titer (Sheahan et al., 2008), and at four DPI, the timepoint at which the QTL on chromosome 16 was mapped (Gralinski et al., 2015). Surprisingly, despite trends for higher mean viral loads in $\mathrm{Muc}^{-1-}$ mice on day 2 and day 4, virus titers were not 
101 significantly different from WT mice at either timepoint (Fig. 3A). Similarly, despite differences in

102 weight loss, viral titer in the lung also exhibited no sex effect (Table S3). Given the distribution

103 of Muc4 in mucosal surfaces, viral load was further interrogated with IHC to determine whether

104 Muc4 might impact viral tropism in a way not readily determined by the measurement of

105 infectious virus per lobe. Upon examining SARS-CoV antigen staining, however, no significant

106 differences in antigen distribution were noted between Muc4 $^{-/-}$and WT mice in either airway or

107 parenchymal staining (Fig. 3B and 3C). Together, the results indicated that the loss of Muc4 had

108 minimal impact on SARS-CoV viral load or distribution.

109

\section{Muc4 $^{-/}$mice have reduced histopathological damage}

Differences in lung damage were assessed using histopathological scoring of H\&E stained lungs harvested at either two or four DPI. Similar to weight loss, the histopathology results demonstrated a clear and consistent sex-based phenotype. Female $M u c 4^{-/-}$mice had a pattern of lower pathology scores than WT mice (Fig. 4). Airway damage (denudation, debris, and inflammation) was minimally present in female $\mathrm{MuC4}^{-/}$at day two or four post-infection (Fig. 4A-C). Similarly, other histopathology and inflammation measures had very low scores in female $\mathrm{Muc4}^{-/-}$mice as compared to female WT mice. In contrast, male $\mathrm{MuC4}^{-/-}$mice induced similar damage to male WT mice (Table S1).

\section{Lung function altered in Muc4-/- female mice}

To further evaluate damage to the lung following infection, whole body plethysmography was utilized to examine changes in pulmonary function (Fig. 5). Using only females, both WT and $\mathrm{Muc4}^{-/-}$mice were challenged with a lower dose $\left(10^{4} \mathrm{PFU}\right)$ to ensure their survival over the full six day time course required to observe the onset, peak, and recovery of disordered lung function following SARS-CoV challenge in mice (Menachery et al., 2015a). Examining airway resistance $(\mathrm{penH})$, the time to peak expiratory flow relative to total expiratory time (rPEF), and 
125

126

127

128

129

130

131

132

133

134

135

136

mid-tidal expiratory flow (EF50), all three measurements had statistically significant differences between SARS-CoV-infected and mock-infected mice within the Muc4 ${ }^{-/}$and WT groups (Supplementary Table S3). However, no Muc4-dependent differences in either penH (Fig. 5A) or rPEF (Fig. 5B) were observed following SARS-CoV infection. In contrast, while not reaching statistical significance, EF50 trended higher in the Muc4 ${ }^{-1-}$ mice as compared to WT mice, peaking at day three post-infection (Fig. 5C). These results show a shift in the early breathing curve in $\mathrm{MuC4}^{-1-}$ mice with more rapid exhalation and more labored breathing. These findings may have been exacerbated with the original, higher dose, but that experiment was precluded by the limited survival of $M u c 4^{-1-}$ mice. Overall, the whole body plethysmography data indicate more difficult breathing for female $\mathrm{Muc4}^{-/}$mice relative to their WT counterparts following SARS-CoV infection.

\section{$\underline{\text { Muc4 }^{-/} \text {mice have augmented inflammation }}$}

Changes in the cytokine and chemokine responses following infection of Muc4 ${ }^{-/}$and WT mice were evaluated at two days post infection. While not significant when adjusted for multiple comparisons (Table S3), key inflammatory cytokines including IL-1 $\beta$, TNF- $\alpha$, and IL6 had increased expression in $\mathrm{Muc4}^{-/-}$mice as compared to WT mice (Fig. 6A-C). Similarly, MIP-1a, MCP-1, and KC also had augmented expression in Muc4 ${ }^{-1-}$ mice (Fig. 6D-F). Notably, the increased values in $\mathrm{Muc4}^{-/-}$mice were maintained across both males and females. Together, the results indicate that $\mathrm{MuC4}^{-/}$mice have augmented inflammatory cytokine responses relative to WT mice, which may contribute to observed differences in pathogenesis.

\section{Muc4 impacts pathogenesis for an unrelated virus}

Because Muc4 modulated SARS-CoV susceptibility independent of viral replication, a cross-platform validation study was undertaken to begin assessing whether the Muc4 had widespread importance in viral pathogenesis. Chinkungunya virus (CHIKV), an alphavirus, 
causes inflammatory arthritis and swelling within the joints in human patients. Importantly, Muc4 has been detected in synovial sarcomas in humans, thus presenting a novel tissue environment and unrelated virus to test the impact of Muc4 (Doyle et al., 2011). Male and

152 female WT and Muc4 $^{-/}$mice were infected with CHIKV and monitored for swelling of the footpad 153 for seven days post infection (Fig. 7). The WT mice have minimal early stage swelling, as was

154 expected with the C57BL/6N model. In contrast, Muc4 ${ }^{-/}$mice have augmented disease early 155 during infection, displaying a biphasic swelling pattern. At days 2-4, both male and female mice 156 have increased footpad swelling compared to control mice. This Muc4-specific difference was 157 not observed during the second swelling event that took place between days six and seven 158 post-infection. Notably, while sex based differences were observed at days two and four post 159 infection, disease was more robust in male mice, contrasting observations seen with SARS-CoV 160 infection. In either sex, however, the loss of Muc4 resulted in augmented disease during early time points and indicates a broad role for Muc4 in viral pathogenesis.

\section{Discussion}

Screening genetically diverse mouse models provides an opportunity to identify natural variation in novel factors which drive viral disease responses. These studies can also provide therapeutic, prophylactic and molecular insights into emerging pathogens, which are difficult to study during the context of an outbreak. Here, prior phenotypic QTL analysis, bioinformatics, and RNA expression analysis were leveraged to identify Muc4 as a high priority candidate gene driving differences in SARS-CoV titer. Utilizing a Muc4 knockout mouse, a role was confirmed for the gene in augmented SARS-CoV pathogenesis. While virus titers trended higher in Muc4 ${ }^{-1-}$ mice at day 2 and 4, there was no statistically significant change as compared to WT control

171 mice. However, in absolute terms the $\mathrm{Muc4}^{-/-}$mice did have a modest $62 \%$ higher titer on day

172 two and a $51 \%$ higher titer on day four as compared to WT, and it is possible that this difference

173 is biologically significant despite the lack of statistical significance as determined by $p$-value 
174 (Lytsy et al., 2018; Vyas et al., 2015). In addition, the loss of Muc4 was linked to enhanced

175 CHIKV disease in vivo. Together, this study highlights both the utility and the challenges in

176 transitioning from QTL hits to single-molecule studies. Our initial hypothesis for Muc4 to play a

177 role in controlling virus replication proved incorrect, or, at the very least, substantially more

178 complex than a simple, direct correlate; however, our exploration found a disease-interaction

179 that played a role in pathogenesis across multiple viruses. proven a challenge to go from a QTL to individual candidate genes (Brown et al., 1997). Even with novel bioinformatic approaches, in the absence of large genomic deletions (Ferris et al., 2013), fortuitously gene-poor regions (Gralinski et al., 2015), or previously identified functions (Gralinski et al., 2017) candidate gene identification continues to be difficult. In this manuscript, we built a framework to integrate knowledge about the preCC genome sequences and a partner microarray dataset to narrow a QTL region down to a likely candidate based on expression correlations. Muc4 exhibited strong correlation data and low expression in the relevant founder strain. Additionally, Muc4 is known to play a role in anti-apoptotic signaling (Chaturvedi et al., 2008; Funes et al., 2006; Moniaux et al., 2007), analysis of published microarray data (Jonckheere $\mathrm{N}$ et al., 2012) reveals that cells lacking Muc4 express lower levels of interferonstimulated genes (Menachery VD, 2014), and the related mucin Muc1 is both anti-apoptotic and 192 anti-inflammatory (Kato K et al., 2014; Li Y et al., 2010; Ueno K et al., 2008). We chose Muc4 193 as our priority candidate gene for follow up, with the initial hypothesis that Muc4 suppressed 194 apoptosis and possible the interferon response, and that its absence in a Muc4 ${ }^{-/-}$mouse would 195 therefore lead to increased apoptosis and inflammation, thereby inhibiting SARS-CoV 196 replication. 
differences in SARS-CoV viral load in the $\mathrm{Muc4}^{-1-}$ mouse strain compared to WT mice. This may be due to sex (discussed more below), differences between naturally occurring SNPs impacting gene structure and expression and ablative knockouts, or the effects of overall genetic background on given gene variants (Leist et al., 2016). The SARS-CoV titer QTL on chromosome 16 was driven by the PWK/PhJ allele, which was strongly associated with lower viral titer and had low expression of Muc4. In contrast, mice with the C56BL/6J allele were associated with high titer and high expression of Muc4. Furthermore, PWK/PhJ mice encode

206 functional variants in Muc4 that are not present in the other seven founder strains. It is

207 therefore possible that C57BL/6 genetic background for the Muc4 ${ }^{-/}$mice, as opposed to a

$208 \mathrm{PWK} / \mathrm{PhJ}$ background, obfuscated any role for Muc4 in the regulation of viral titer; this possibility 209 is especially relevant given that the hypothesized role of Muc4 is in the context of complex 210 signaling pathways requiring multiple molecular partners, rather than a direct role such as the 211 physical barrier function of mucins. Alternatively, Muc4 may simply not impact viral titer following

212 SARS-CoV infection; this leaves the possibility that other genetic targets within the chromosome

21316 QTL are responsible for limiting SARS-CoV titers at later time points. Furthermore, the

214 existence of multiple titer-driven QTLs reaffirms that no single gene is expected to serve as the 215 sole driver of SARS-CoV titer. Yet, despite the lack of QTL validation, these studies still 216 identified a role for Muc4 in viral pathogenesis.

A surprising outcome from these studies was the demonstration of sex-specific and 218 increased disease severity in $\mathrm{Muc4}^{-1-}$ female mice infected with SARS-CoV. Females lacking 219 Muc4 consistently demonstrated increased susceptibility to SARS-CoV-induced disease, while 220 males did not. These results affirm the National Institute of Health emphasis on conducting 221 animal studies in both male and female subjects (Clayton and Collins, 2014; National Institutes 222 of Health, 2015). Interestingly, SARS-CoV has been reported to cause more severe disease in 223 male mice, with the female mice deriving their resistance at least in part from estrogen signaling 
224 (Channappanavar et al., 2017). Furthermore, epidemiological data from both SARS-CoV and 225 SARS-CoV-2 indicate that human females may be more resistant than human males (Chen et 226 al., 2020; Huang et al., 2020; Karlberg et al., 2004; Leong et al., 2006). Estrogen increases

227 Muc4 transcription in a tissue-specific manner (Lange et al., 2003), offering a potential

228 mechanism as to the greater impact of Muc4's absence in female mice. Sex effects in the 229 context of Muc4 have also been reported in a murine model of colitis and colitis-associated 230 colorectal cancer (Das et al., 2016). These results hint that the role of Muc4 may differ in males 231 and females based upon factors inherent to the host, such as localization, expression levels, or 232 interactions with hormone signaling pathways, and may be less dependent on factors that are 233 unique to a particular disease model. infection of female $\mathrm{Muc4}^{-/-}$mice, and CHIKV infection of both male and female $\mathrm{Muc}^{-/-}$mice, resulted in more severe disease following infection. For SARS-CoV, loss of Muc4 exacerbated weight loss and increased lethality; surprisingly, less histopathologic damage was observed in the $\mathrm{MuC4}^{-/-}$lungs following infection despite augmented inflammatory cytokines. The results suggest that the loss of Muc4 may exacerbate systemic disease and delay the repair/recovery

240 processing in the lung following SARS-CoV infection. A similar reduction in histopathology 241 damage was observed with MERS-CoV infection of immunocompromised rhesus macaques 242 providing evidence for this theory (Prescott et al., 2018). Notably, footpad swelling following $243 \mathrm{CHIKV}$ infection is representative of systemic disease and is exacerbated in the absence of 244 Muc4. Although speculative, it is possible that Muc4 functions not to modulate local viral 245 replication, but rather to limit disseminated disease. Clearly, more studies are needed to 246 unravel these complex interactions. 
absence of Muc4 exacerbates disease in two unrelated viruses. The SARS-CoV and CHIKV results indicate that Muc4 has a role in regulating susceptibility and may be widespread across viral pathogens. The study of mucin-driven cell signaling and its role in viral pathogenesis

252 represents a novel avenue of research with the potential to identify new anti-viral therapeutic 253 targets.

Materials and Methods

The generation of C57BL/6NTac Muc4 ${ }^{\text {tm1Unc }}$ mice, kindly provided by Dr. Scott Randell of 257 the University of North Carolina at Chapel Hill and hereafter referred to as $\mathrm{Muc4}^{-/-}$mice, was 258 described by Rowson-Hodel et al (Rowson-Hodel et al., 2018). The C57BL/6NTac genetic 259 background of these mice was confirmed in our hands via utilization of the MiniMUGA genotyping array (Neogen Inc, Lincoln, NE), a new genotyping array which includes diagnostic markers for the substrain origin of many inbred mouse strains. Age- and sex-matched wild-type control C57BL/6NTac mice (hereafter referred to as WT mice) were obtained from Taconic 263 (Germantown, NY). Ten- to eleven-week-old mice were anesthetized with a mixture of 264 ketamine (Zoetis, Kalamazoo, MI) and xylazine (Akorn Animal Health, Lake Forest, IL) and inoculated intranasally with either PBS (Gibco, Grand Island, NY), $1 \times 10^{4}$ PFU, or $1 \times 10^{5}$ PFU of recombinant mouse adapted SARS-CoV (rMA15) in a 50 $\mathrm{ll}$ volume (Roberts et al.). Mice

267 receiving the $1 \times 10^{5}$ PFU dose and their mock-infected counterparts were weighed daily and were euthanized at either two or four days post-infection (DPI). The inferior lobe was harvested and stored intact at $-80^{\circ} \mathrm{C}$ in $1 \mathrm{ml}$ PBS with glass beads for downstream titration, and the postcaval lobe was similarly stored for downstream cytokine and chemokine analysis. The left lobe 271 was stored at $4^{\circ} \mathrm{C}$ in $10 \%$ buffered paraformaldehyde (Fisher Scientific, Fair Lawn, NJ) for at 272 least seven days for downstream histopathology and immunohistochemistry. Mice receiving the $2731 \times 10^{4}$ PFU dose and their mock-infected counterparts were weighed daily and their lung 
274 function was assessed via whole body plethysmography with in Buxco FinePoint system (Data

275 Sciences International, New Brighton, MN) from one day prior to infection through six DPI. All

276 data from SARS-CoV infections is summarized in Table S1.

277 Seven-week-old mice were anesthetized with isoflurane (Primal Enterprises, Andrha

278 Pradesh, India) and inoculated subcutaneously in the left rear footpad with either diluent (PBS

279 supplemented with $1 \% \mathrm{FBS}, 1 \mathrm{mM} \mathrm{CaCl}_{2}$, and $0.5 \mathrm{mM} \mathrm{MgCl}_{2}$ ) or $100 \mathrm{PFU}$ of recombinant

280 chikungunya virus (CHIKV) SL15649 in a 10 1 l volume (Morrison et al., 2011). Footpad size was

281 measured and recorded daily using a caliper to measure the vertical height of the ball of the left

282 rear foot. Mice were humanely euthanized at seven DPI. All data from CHIKV infections is 283 summarized in Table S2.

\section{Lung Titration}

Lung samples were thawed at $37^{\circ}$ and lysed for 60 seconds at $6,000 \mathrm{rpm}$ in a MagNA Lyser (Roche, Mannheim, Germany). Debris was pelleted, and lung homogenate was serially diluted 10-fold in PBS. Vero E6 cell monolayers in 6-well plates were infected with 200 $\mu$ l of diluted lung homogenate $\left(10^{-1}-10^{-6}\right)$ for one hour at $37^{\circ} \mathrm{C}$ with $5 \% \mathrm{CO}_{2}$. Monolayers were

291 Rockland, ME). At two DPI plates were stained with neutral red (Fisher Scientific, Fair Lawn, 292 NJ) for approximately four hours and plaques were visualized with a light box.

\section{Cytokine Analysis}

294 Cytokine production was measured using the Bio-Plex Pro Mouse Cytokine 23-plex Assay (Bio295 Rad, Hercules, CA) on the MAGPIX Multiplex Reader (Bio-Rad, Hercules, CA) according to the manufacturer's instructions. Lung samples were homogenized and clarified as described for the lung titration assay prior to analysis. 
Histopathology and Immunohistochemistry

Formalin-fixed lobes were embedded in paraffin and $4 \mu \mathrm{m}$ sections were mounted on either Superfrost slides (Fisher Scientific, Waltham, MA) for hematoxylin and eosin staining or on ProbeOn slides (Fisher Scientific, Waltham, MA) for immunohistochemistry (IHC).

302 Embedding, mounting, and hematoxylin and eosin staining was performed by the LCCC Animal Histopathology Core Facility at the University of North Carolina at Chapel Hill. and $1 \%$ nonfat milk (Lab Scientific, Highlands, NJ) in TBS for two hours at room temperature. Rabbit anti-SARS-CoV nucleocapsid polyclonal antibody (PA1-41098, Thermo Scientific, Rockford, IL) diluted 1:2,000 in blocking buffer was allowed to bind overnight at $4^{\circ} \mathrm{C}$. Slides were washed three times in TBS with $0.025 \%$ Triton X-100 (TBST) (Sigma, St. Louis, MO), then incubated in $0.3 \% \mathrm{H}_{2} \mathrm{O} 2$ in TBS for 15 minutes to prevent endogenous peroxidases from 312 generating a background signal. Slides were incubated with horseradish peroxidase-conjugated 313 goat anti-rabbit IgG secondary antibody (ab97051, Abcam, Cambridge, MA) diluted 1:1,000 in 314 blocking buffer for one hour in a humidity box, then washed three times in TBST. Slides were 315 developed using the Metal Enhanced DAB Substrate Kit (Thermo Scientific, Rockford, IL) and counterstained with Richard-Allan Scientific Modified Mayer's Hematoxylin (Thermo Scientific,

317 Rockford, IL) and 0.2M lithium carbonate (Sigma, St. Louis, MO) prior to rehydration and 318 mounting. All scoring was conducted in a blinded fashion on a severity scale of 0 (none) to 3 319 (severe). 
RNA expression levels were analyzed by one-way ANOVA with Dunnett's multiple

322 comparisons test comparing PWK/PhJ to the other seven CC founder lines using Prism 7 for Windows version 7.01 (GraphPad Software, La Jolla, CA). Buxco data was transformed as previously described (Menachery et al., 2015a) Daily results for all titer-related data types ( $\log _{10}$-transformed viral load and immunohistochemistry) and cytokine levels were analyzed by two-way ANOVA using RStudio version 1.1.383 with R version 3.2.0 (R Core Team, 2017; RStudio Team, 2015) to determine the impact of mouse strain and sex. Transformed daily Buxco results were similarly analyzed by two-way ANOVA to determine the impact of infection and mouse strain. Daily results for all pathology-related data types (histopathology, weight change, and footpad swelling) was analyzed by three-way ANOVA to determine the impact of mouse strain, sex, and infection status. When three-way ANOVA results indicated significant differences on the basis of sex (weight loss, histopathology, and footpad swelling), the strainbased differences between infected animals of a single sex were analyzed using multiple t-tests with the Benjamini and Hochberg correction for false discoveries in Prism. All graphing was done in Prism. A significance threshold of $>0.05$ after correction for multiple comparisons was considered significant throughout all studies. The results of all statistical analyses are summarized in Table S3.

Data Availability

All phenotypic data associated with the infection of $M u c 4^{-1-}$ mice and their WT counterparts are summarized in Table S1 and S2. $\mathrm{Muc}^{-/-}$mice are available upon request.

\section{Funding}

JAP, LEG, MTF, MTH and RSB were funded by NIH NIAID (U19 Al 100625, U19 Al 109761, and U54 Al 081680). KSP was funded by NIH NIAID (T32 Al 007151-36A1 and F32 Al 126730). AB was funded by NIH NIAID (T32 Al 7419-22). VDM was funded by the NIH NIA 
345 (K99 AG 049092). The funders had no role in study design, data collection and interpretation,

346 or the decision to submit the work for publication.

\section{Author Contributions}

348 JAP was involved with the design of all experiments, performed all SARS-CoV mouse 349 experiments, and prepared the manuscript. KSP and MTH designed and performed the CHIKV 350 mouse experiments. LEG provided feedback regarding experimental design and performed 351 SARS-CoV mouse experiments and BioPlex analysis. AB performed immunohistochemistry 352 staining. VDM provided feedback regarding experimental design, assisted with SARS-CoV 353 mouse experiments, and assisted substantially with the editing of the manuscript. MTF 354 provided guidance regarding statistical analysis. MTF, DB, and SKM performed array analysis 355 and assisted with the selection of Muc4 from the list of potential target genes. RSB scored 356 gross pathology and immunohistochemistry and contributed to all aspects of study design, 357 experimental design, and manuscript design and editing.

\section{Acknowledgements}

359 The authors thank Dr. Scott H. Randell of the Department of Cell Biology and Physiology at the 360 University of North Carolina at Chapel Hill for contributing the Muc4 ${ }^{-/}$mice, without which these 361 studies would not have been possible. 


\section{References}

Andrianifahanana, M., Moniaux, N., Schmied, B.M., Ringel, J., Friess, H., Hollingsworth, M.A., Buchler, M.W., Aubert, J.P., Batra, S.K., 2001. Mucin (MUC) gene expression in human pancreatic adenocarcinoma and chronic pancreatitis: A potential role of MUC4 as a tumor marker of diagnostic significance. Clinical Cancer Research 7, 4033-4040.

Aylor, D.L., Valdar, W., Foulds-Mathes, W., Buus, R.J., Verdugo, R.A., Baric, R.S., Ferris, M.T., Frelinger, J.A., Heise, M., Frieman, M.B., Gralinski, L.E., Bell, T.A., Didion, J.D., Hua, K., Nehrenberg, D.L., Powell, C.L., Steigerwalt, J., Xie, Y., Kelada, S.N., Collins, F.S., Yang, I.V., Schwartz, D.A., Branstetter, L.A., Chesler, E.J., Miller, D.R., Spence, J., Liu, E.Y., McMillan, L., Sarkar, A., Wang, J., Wang, W., Zhang, Q., Broman, K.W., Korstanje, R., Durrant, C., Mott, R., Iraqi, F.A., Pomp, D., Threadgill, D., de Villena, F.P., Churchill, G.A., 2011. Genetic analysis of complex traits in the emerging Collaborative Cross. Genome Res 21, 1213-1222.

Bernacki, S.H., Nelson, A.L., Abdullah, L., Sheehan, J.K., Harris, A., Davis, C.W., Randell, S.H., 1999. Mucin gene expression during differentiation of human airway epithelia in vitro. Muc4 and muc5b are strongly induced. Am J Respir Cell Mol Biol 20, 595-604.

Brown, M.G., Scalzo, A.A., Matsumoto, K., Yokoyama, W.M., 1997. The natural killer gene complex: a genetic basis for understanding natural killer cell function and innate immunity. Immunol Rev 155, 53-65.

Channappanavar, R., Fett, C., Mack, M., Ten Eyck, P.P., Meyerholz, D.K., Perlman, S., 2017. Sex-Based Differences in Susceptibility to Severe Acute Respiratory Syndrome Coronavirus Infection. J Immunol 198, 4046-4053.

Chaturvedi, P., Singh, A.P., Batra, S.K., 2008. Structure, evolution, and biology of the MUC4 mucin. FASEB J 22, 966-981.

Chen, N., Zhou, M., Dong, X., Qu, J., Gong, F., Han, Y., Qiu, Y., Wang, J., Liu, Y., Wei, Y., Xia, J., Yu, T., Zhang, X., Zhang, L., 2020. Epidemiological and clinical characteristics of 99 cases of 2019 novel coronavirus pneumonia in Wuan, China: a descriptive study. Lancet 395, 507-513.

Churchill, G.A., Airey, D.C., Allayee, H., Angel, J.M., Attie, A.D., Beatty, J., Beavis, W.D., Belknap, J.K., Bennett, B., Berrettini, W., Bleich, A., Bogue, M., Broman, K.W., Buck, K.J., Buckler, E., Burmeister, M., Chesler, E.J., Cheverud, J.M., Clapcote, S., Cook, M.N., Cox, R.D., Crabbe, J.C., Crusio, W.E., Darvasi, A., Deschepper, C.F., Doerge, R.W., Farber, C.R., Forejt, J., Gaile, D., Garlow, S.J., Geiger, H., Gershenfeld, H., Gordon, T., Gu, J., Gu, W., de Haan, G., Hayes, N.L., Heller, C., Himmelbauer, H., Hitzemann, R., Hunter, K., Hsu, H.C., Iraqi, F.A., Ivandic, B., Jacob, H.J., Jansen, R.C., Jepsen, K.J., Johnson, D.K., Johnson, T.E., Kempermann, G., Kendziorski, C., Kotb, M., Kooy, R.F., Llamas, B., Lammert, F., Lassalle, J.M., Lowenstein, P.R., Lu, L., Lusis, A., Manly, K.F., Marcucio, R., Matthews, D., Medrano, J.F., Miller, D.R., Mittleman, G., Mock, B.A., Mogil, J.S., Montagutelli, X., Morahan, G., Morris, D.G., Mott, R., Nadeau, J.H., Nagase, H., Nowakowski, R.S., O'Hara, B.F., Osadchuk, A.V., Page, G.P., Paigen, B., Paigen, K., Palmer, A.A., Pan, H.J., Peltonen-Palotie, L., Peirce, J., Pomp, D., Pravenec, M., Prows, D.R., Qi, Z., Reeves, R.H., Roder, J., Rosen, G.D., Schadt, E.E., Schalkwyk, L.C., Seltzer, Z., Shimomura, K., Shou, S., Sillanpää, M.J., Siracusa, L.D., Snoeck, H.W., Spearow, J.L., Svenson, K., Tarantino, L.M., Threadgill, D., Toth, L.A., Valdar, W., de Villena, F.P., Warden, C., Whatley, S., Williams, R.W., Wiltshire, T., Yi, N., Zhang, D., Zhang, M., Zou, F., Consortium, C.T., 2004. The Collaborative Cross, a community resource for the genetic analysis of complex traits. Nat Genet 36, 1133-1137. 
Clayton, J.A., Collins, F.S., 2014. Policy: NIH to balance sex in cell and animal studies. Nature 509, 282-283.

Coleman, C.M., Frieman, M.B., 2013. Emergence of the Middle East respiratory syndrome coronavirus. PLoS Pathog 9, e1003595.

Collaborative Cross Consortium., 2012. The genome architecture of the Collaborative Cross mouse genetic reference population. Genetics 190, 389-401.

Das, S., Rachagani, S., Sheinin, Y., Smith, L.M., Gurumurthy, C.B., Roy, H.K., Batra, S.K., 2016. Mice deficient in Muc4 are resistant to experimental colitis and colitis-associated colorectal cancer. Oncogene 35, 2645-2654.

Daugherty, M.D., Young, J.M., Kerns, J.A., Malik, H.S., 2014. Rapid evolution of PARP genes suggests a broad role for ADP-ribosylation in host-virus conflicts. PLoS Genet 10, e1004403.

Doyle, L.A., Moller, E., Dal Cin, P., Fletcher, C.D., Mertens, F., Hornick, J.L., 2011. MUC4 is a highly sensitive and specific marker for low-grade fibromyxoid sarcoma. Am J Surg Pathol 35, 733-741.

Eckei, L., Krieg, S., Butepage, M., Lehmann, A., Gross, A., Lippok, B., Grimm, A.R., Kummerer, B.M., Rossetti, G., Luscher, B., Verheugd, P., 2017. The conserved macrodomains of the nonstructural proteins of Chikungunya virus and other pathogenic positive strand RNA viruses function as mono-ADP-ribosylhydrolases. Sci Rep 7, 41746.

Fellay, J., Shianna, K.V., Ge, D., Colombo, S., Ledergerber, B., Weale, M., Zhang, K., Gumbs, C., Castagna, A., Cossarizza, A., Cozzi-Lepri, A., De Luca, A., Easterbrook, P., Francioli, P., Mallal, S., Martinez-Picado, J., Miro, J.M., Obel, N., Smith, J.P., Wyniger, J., Descombes, P., Antonarakis, S.E., Letvin, N.L., McMichael, A.J., Haynes, B.F., Telenti, A., Goldstein, D.B., 2007. A whole-genome association study of major determinants for host control of HIV-1. Science 317, 944-947.

Ferris, M.T., Aylor, D.L., Bottomly, D., Whitmore, A.C., Aicher, L.D., Bell, T.A., BradelTretheway, B., Bryan, J.T., Buus, R.J., Gralinski, L.E., Haagmans, B.L., McMillan, L., Miller, D.R., Rosenzweig, E., Valdar, W., Wang, J., Churchill, G.A., Threadgill, D.W., McWeeney, S.K., Katze, M.G., Pardo-Manuel de Villena, F., Baric, R.S., Heise, M.T., 2013. Modeling host genetic regulation of influenza pathogenesis in the collaborative cross. PLoS Pathog 9, e1003196.

Funes, M., Miller, J.K., Lai, C., Carraway, K.L., Sweeney, C., 2006. The mucin muc4 potentiates neuregulin signaling by increasing the cell-surface populations of ErbB2 and ErbB3. Journal of Biological Chemistry 281, 19310-19319.

Ge, D., Fellay, J., Thompson, A.J., Simon, J.S., Shianna, K.V., Urban, T.J., Heinzen, E.L., Qiu, P., Bertelsen, A.H., Muir, A.J., Sulkowski, M., McHutchison, J.G., Goldstein, D.B., 2009. Genetic variation in IL28B predicts hepatitis C treatment-induced viral clearance. Nature 461, 399-401.

Gipson, I.K., 2001. Mucins of the human endocervix. Front Biosci 6, D1245-1255.

Gipson, I.K., 2004. Distribution of mucins at the ocular surface. Exp Eye Res 78, 379-388.

Gorbalenya, A.E., Baker, S.C., Baric, R.S., de Groot, R.J., Drosten, C., Gulyaeva, A.A., Haagmans, B.L., Lauber, C., Leontovich, A.M., Neuman, B.W., Penzar, D., Perlman, S., Poon, L.L.M., Samborskiy, D., Sidorov, I.A., Sola, I., Ziebuhr, J, 2020. Severe acute respiratory syndrome-related coronavirus: The species and its viruses - a statement of the Coronavirus Study Group. bioRxiv 2020.02.07.937862. 
Gralinski, L.E., Ferris, M.T., Aylor, D.L., Whitmore, A.C., Green, R., Frieman, M.B., Deming, D., Menachery, V.D., Miller, D.R., Buus, R.J., Bell, T.A., Churchill, G.A., Threadgill, D.W., Katze, M.G., McMillan, L., Valdar, W., Heise, M.T., Pardo-Manuel de Villena, F., Baric, R.S., 2015. Genome Wide Identification of SARS-CoV Susceptibility Loci Using the Collaborative Cross. PLoS Genet 11, e1005504.

Gralinski, L.E., Menachery, V.D., Morgan, A.P., Totura, A.L., Beall, A., Kocher, J., Plante, J., Corinne Harrison-Shostak, D., Schäfer, A., Pardo-Manuel de Villena, F., Ferris, M.T., Baric, R.S, 2017. Allelic Variation in the Toll-Like Receptor Adaptor Protein Ticam2 Contributes to SARSCoronavirus Pathogenesis in Mice. G3 7, 1653-1663.

Gralinski, L.E., Menachery V.D., 2020. Return of the Coronavirus: 2019-nCoV. Viruses Jan 24;12(2). pii: v12020135.

Grunewald, M.E., Chen, Y., Kuny, C., Maejima, T., Lease, R., Ferraris, D., Aikawa, M., Sullivan, C.S., Perlman, S., Fehr, A.R., 2019. The coronavirus macrodomain is required to prevent PARP-mediated inhibition of virus replication and enhancement of IFN expression. PLoS Pathog 15, e1007756.

Huang, C., Wang., Y., Li, X., Ren, L., Zhao, J., Hu., Y., Zhang, L., Fan, G., Xu, J., Gu, X., Cheng, Z., Yu, T., Xia, J., Wei, Y., Wu, W., Xie, X., Yin, W., Liu, M., Xiao, Y., Gao, H., Guo, L., Xie, J., Wang, G., Jiang, R., Gao, Z., Jin, Q., 2020. Clinical features of patients infected with 2019 novel coronavirus in Wuhan China. The Lancet 395, 497-506.

Jonckheere, N., Skrypek, N., Merlin, J., Dessein, A.F., Dumont, P., Leteurtre, E., Harris, A., Desseyn, J.L., Susini, C., Frénois, F., Van Seuningen, I., 2012. The mucin MUC4 and its membrane partner ErbB2 regulate biological properties of human CAPAN-2 pancreatic cancer cells via different signalling pathways. PLoS One 7, e32232.

Kamikawa, Y., Kanmura, Y., Hamada, T., Yamada, N., Macha, M.A., Batra, S.K., Higashi, M., Yonezawa, S., Sugihara, K., 2015. Combination of MUC1 and MUC4 expression predicts clinical outcome in patients with oral squamous cell carcinoma. International Journal of Clinical Oncology 20, 298-307.

Karlberg, J., Chong, D.S., Lai, W.Y., 2004. Do men have a higher case fatality rate of severe acute respiratory syndrome than women do? American Journal of Epidemiology 159, 229-231.

Kato, K., Lillehoj, E.P., Kim, K.C., 2014. MUC1 regulates epithelial inflammation and apoptosis by Polyl:C through inhibition of Toll/IL-1 receptor-domain-containing adapter-inducing IFN-beta (TRIF) recruitment to Toll-like receptor 3. Am J Respir Cell Mol Biol 51, 446-454.

Keane, T.M., Goodstadt, L., Danecek, P., White, M.A., Wong, K., Yalcin, B., Heger, A., Agam, A., Slater, G., Goodson, M., Furlotte, N.A., Eskin, E., Nellaker, C., Whitley, H., Cleak, J., Janowitz, D., Hernandez-Pliego, P., Edwards, A., Belgard, T.G., Oliver, P.L., Mclntyre, R.E., Bhomra, A., Nicod, J., Gan, X., Yuan, W., van der Weyden, L., Steward, C.A., Bala, S., Stalker, J., Mott, R., Durbin, R., Jackson, I.J., Czechanski, A., Guerra-Assuncao, J.A., Donahue, L.R., Reinholdt, L.G., Payseur, B.A., Ponting, C.P., Birney, E., Flint, J., Adams, D.J., 2011. Mouse genomic variation and its effect on phenotypes and gene regulation. Nature 477, 289-294.

Kesimer, M., Ehre, C., Burns, K.A., Davis, C.W., Sheehan, J.K., Pickles, R.J., 2013. Molecular organization of the mucins and glycocalyx underlying mucus transport over mucosal surfaces of the airways. Mucosal Immunol 6, 379-392.

Komatsu, M., Jepson, S., Arango, M.E., Carraway, C.A.C., Carraway, K.L., 2001. Muc4/sialomucin complex, an intramembrane modulator of ErbB2/HER2/Neu, potentiates 
primary tumor growth and suppresses apoptosis in a xenotransplanted tumor. Oncogene 20, 461-470.

Lange, C., Fernandez, J., Shim, D., Spurr-Michaud, S., Tisdale, A., Gipson, I.K., 2003. Mucin gene expression is not regulated by estrogen and/or progesterone in the ocular surface epithelia of mice. Exp Eye Res 77, 59-68.

Leist, S.R., Kollmus, H., Hatesuer, B., Lambertz, R.L., Schughart, K., 2016. Lst1 deficiency has a minor impact on course and outcome of the host response to influenza A H1N1 infections in mice. Virology journal 13, 17.

Leong, H.N., Earnest, A., Lim, H.H., Chin, C.F., Tan, C., Puhaindran, M.E., Tan, A., Chen, M.I., Leo, Y.S., 2006. SARS in Singapore - predictors of disease severity. Ann Acad Med Singapore 35: 326-331.

Li, Y., Dinwiddie, D.L., Harrod, K.S., Jiang, Y., Kim, K.C., 2010. Anti-inflammatory effect of MUC1 during respiratory syncytial virus infection of lung epithelial cells in vitro. Am J Physiol Lung Cell Mol Physiol 298, L558-563.

Lindesmith, L., Moe, C., Marionneau, S., Ruvoen, N., Jiang, X., Lindblad, L., Stewart, P., LePendu, J., Baric, R., 2003. Human susceptibility and resistance to Norwalk virus infection. Nat Med 9, 548-553.

Liu, B., Offner, G.D., Nunes, D.P., Oppenheim, F.G., Troxler, R.F., 1998. MUC4 is a major component of salivary mucin MG1 secreted by the human submandibular gland. Biochem Biophys Res Commun 250, 757-761.

López, C., Saravia, C., Gomez, A., Hoebeke, J., Patarroyo, M.A., 2010. Mechanisms of genetically-based resistance to malaria. Gene 467, 1-12.

Lytsy, P. 2018. P in the right place: Revisiting the evidential value of P-values. J Evid Based Med 11, 288-291.

Macha, M.A., Rachagani, S., Pai, P., Gupta, S., Lydiatt, W.M., Smith, R.B., Johansson, S.L., Lele, S.M., Kakar, S.S., Farghaly, H., Lee, J.H., Meza, J., Ganti, A.K., Jain, M., Batra, S.K., 2015. MUC4 regulates cellular senescence in head and neck squamous cell carcinoma through p16/Rb pathway. Oncogene 34, 2814.

Menachery, V.D., Eisfeld, A.J., Schäfer, A., Josset, L., Sims, A.C., Proll, S., Fan, S., Li, C., Neumann, G., Tilton, S.C., Chang, J., Gralinski, L.E., Long, C., Green, R., Williams, C.M., Weiss, J., Matzke, M.M., Webb-Robertson, B.J., Schepmoes, A.A., Shukla, A.K., Metz, T.O., Smith, R.D., Water, K.M., Katze, M.G., Kawaoka, Y., Baric, R.S., 2014. mBio 5, e01174-14.

Menachery, V.D., Gralinski, L.E., Baric, R.S., Ferris, M.T., 2015a. New Metrics for Evaluating Viral Respiratory Pathogenesis. PLoS One 10, e0131451.

Menachery, V.D., Yount, B.L., Jr., Sims, A.C., Debbink, K., Agnihothram, S.S., Gralinski, L.E., Graham, R.L., Scobey, T., Plante, J.A., Royal, S.R., Swanstrom, J., Sheahan, T.P., Pickles, R.J., Corti, D., Randell, S.H., Lanzavecchia, A., Marasco, W.A., Baric, R.S., 2016. SARS-like WIV1-CoV poised for human emergence. Proc Natl Acad Sci U S A 113, 3048-3053.

Menachery, V.D., Yount Jr, B.L., Debbink, K., Agnihothram, S., Gralinski, L.E., Plante, J.A., Graham, R.L., Scobey, T., Ge, X.-Y., Donaldson, E.F., Randell, S.H., Lanzavecchia, A., Marasco, W.A., Shi, Z.-L., Baric, R.S., 2015b. A SARS-like cluster of circulating bat coronaviruses shows potential for human emergence. Nat Med advance online publication. 
Moniaux, N., Chaturvedi, P., Varshney, G.C., Meza, J.L., Rodriguez-Sierra, J.F., Aubert, J.P., Batra, S.K., 2007. Human MUC4 mucin induces ultra-structural changes and tumorigenicity in pancreatic cancer cells. Br J Cancer 97, 345-357.

Morrison, T.E., Oko, L., Montgomery, S.A., Whitmore, A.C., Lotstein, A.R., Gunn, B.M., Elmore, S.A., Heise, M.T., 2011. A mouse model of chikungunya virus-induced musculoskeletal inflammatory disease: evidence of arthritis, tenosynovitis, myositis, and persistence. Am J Pathol 178, 32-40.

Mukhopadhyay, P., Lakshmanan, I., Ponnusamy, M.P., Chakraborty, S., Jain, M., Pai, P., Smith, L.M., Lele, S.M., Batra, S.K., 2013. MUC4 Overexpression Augments Cell Migration and Metastasis through EGFR Family Proteins in Triple Negative Breast Cancer Cells. Plos One 8.

National Institutes of Health, 2015. Consideration of Sex as a Biological Variable in NIH-funded Research.

Prescott, J., Falzarano, D., de Wit, E., Hardcastle, K., Feldmann, F., Haddock, E., Scott, D., Feldmann, H., Munster, V.J., 2018. Pathogenicity and Viral Shedding of MERS-CoV in Immunocompromised Rhesus Macaques. Front Immunol 9.

R Core Team, 2017. R: A Language and Environment for Statistical Computing, 3.4.2 ed. R Foundation for Statistical Computing, Vienna, Austria.

Reid, C.J., Gould, S., Harris, A., 1997. Developmental expression of mucin genes in the human respiratory tract. Am J Respir Cell Mol Biol 17, 592-598.

Roberts, A., Deming, D., Paddock, C.D., Cheng, A., Yount, B., Vogel, L., Herman, B.D., Sheahan, T., Heise, M., Genrich, G.L., Zaki, S.R., Baric, R., Subbarao, K., 2007. A mouseadapted SARS-coronavirus causes disease and mortality in BALB/c mice. PLoS Pathog 3, e5.

Rowson-Hodel, A.R., Wald, J.H., Hatakeyama, J., O'Neal, W.K., Stonebraker, J.R., VanderVorst, K., Saldana, M.J., Borowsky, A.D., Sweeney, C., Carraway, K.L., 3rd, 2018. Membrane Mucin Muc4 promotes blood cell association with tumor cells and mediates efficient metastasis in a mouse model of breast cancer. Oncogene 37, 197-207.

RStudio Team, 2015. RStudio: Integrated Development Environment for R, 0.99.467 ed. RStudio, Inc., Boston, MA.

Sheahan, T., Morrison, T.E., Funkhouser, W., Uematsu, S., Akira, S., Baric, R.S., Heise, M.T., 2008. MyD88 is required for protection from lethal infection with a mouse-adapted SARS-CoV. PLoS Pathog 4, e1000240.

Singh, A.P., Moniaux, N., Chauhan, S.C., Meza, J.L., Batra, S.K., 2004. Inhibition of MUC4 expression suppresses pancreatic tumor cell growth and metastasis. Cancer Research 64, 622630.

Tamura, Y., Higashi, M., Kitamoto, S., Yokoyama, S., Osako, M., Horinouchi, M., Shimizu, T., Tabata, M., Batra, S.K., Goto, M., Yonezawa, S., 2012. MUC4 and MUC1 Expression in Adenocarcinoma of the Stomach Correlates with Vessel Invasion and Lymph Node Metastasis: An Immunohistochemical Study of Early Gastric Cancer. Plos One 7.

Ueno, K., Koga, T., Kato, K., Golenbock, D.T., Gendler, S.J., Kai, H., Kim, K.C., 2008. MUC1 mucin is a negative regulator of toll-like receptor signaling. Am J Respir Cell Mol Biol 38, 263268. 
576 UNC Systems Genetics Core Facility, 2012. The Collaborative Cross Homepage.

577 http://csbio.unc.edu/CCstatus/index.py. Accessed 30 November 2015.

578 Vyas, D., Balakrishnan, A., Vyas, A., 2015. The Value of the P Value. Am J Robot Surg 2, 53-

57956.

580 World Health Organization, 2020. Coronavirus disease 2019 (COVID-19) - Situation Report 23.

581 https://www.who.int/docs/default-source/coronaviruse/situation-reports/20200212-sitrep-23-

582 ncov.pdf?sfvrsn=41e9fb78 2. Accessed 12 February 2020.

583 Yang, H., Bell, T.A., Churchill, G.A., Pardo-Manuel de Villena, F., 2007. On the subspecific 584 origin of the laboratory mouse. Nat Genet 39, 1100-1107.

585 Yang, H., Ding, Y., Hutchins, L.N., Szatkiewicz, J., Bell, T.A., Paigen, B.J., Graber, J.H., de 586 Villena, F.P., Churchill, G.A., 2009. A customized and versatile high-density genotyping array for 587 the mouse. Nat Methods 6, 663-666.

588 Yang, H., Wang, J.R., Didion, J.P., Buus, R.J., Bell, T.A., Welsh, C.E., Bonhomme, F., Yu, A.H., 589 Nachman, M.W., Pialek, J., Tucker, P., Boursot, P., McMillan, L., Churchill, G.A., de Villena, 590 F.P., 2011. Subspecific origin and haplotype diversity in the laboratory mouse. Nat Genet 43, $591648-655$. 

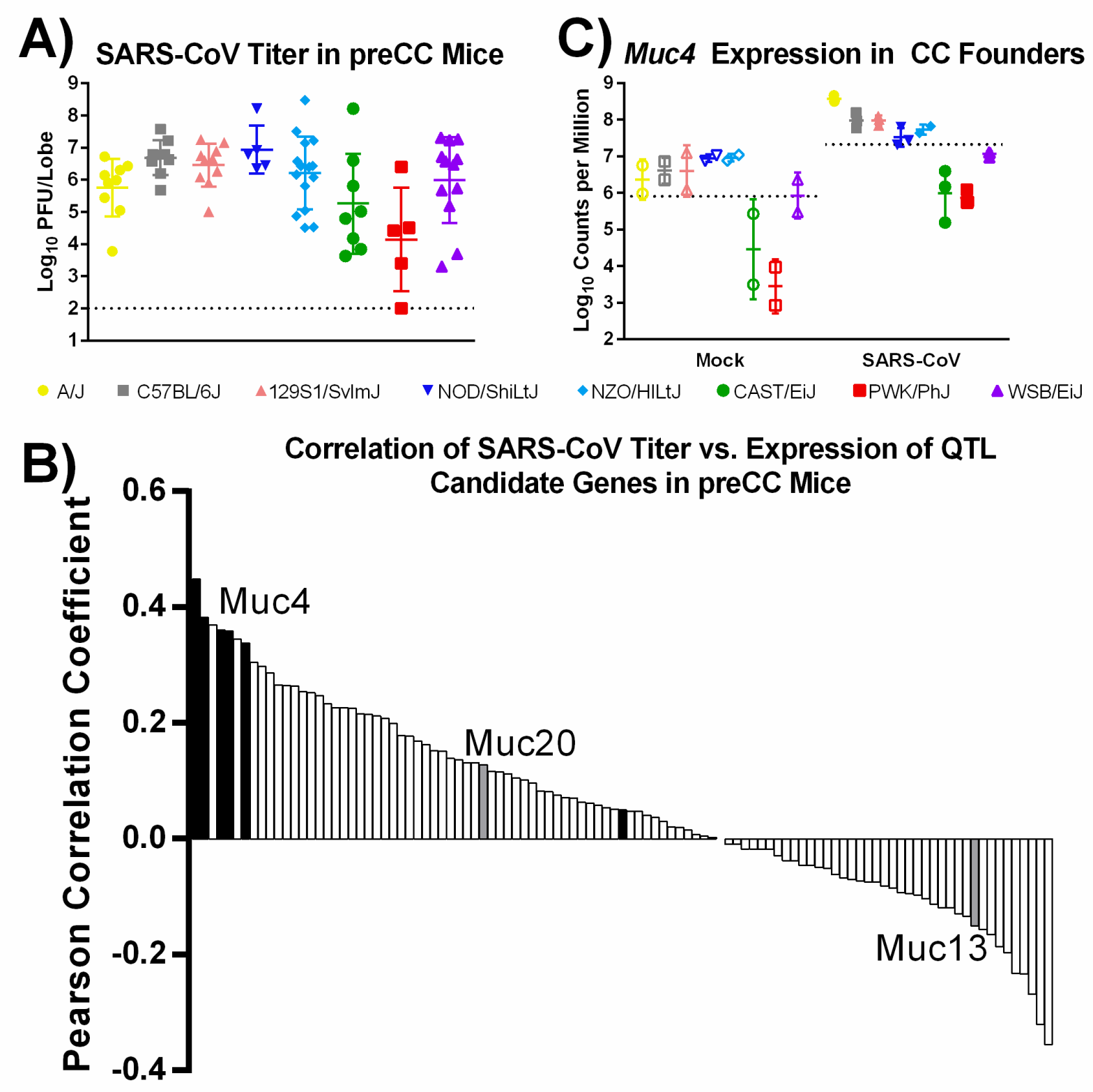

Fig. 1. Selection of Muc4 as a candidate gene from the preCC screen of SARS-CoV lung titer. (A) SARSCoV lung titer at four DPI in preCC mice that were homozygous for one of the eight indicated founder strains at genotype marker nearest to the Muc4 gene. Dashed line represents the lower limit of detection for the assay. (B) Correlation values for $\log _{10}$-transformed viral titers and host RNA expression values as determined by microarray in the lungs of preCC mice at four DPI with SARS-CoV. Bars correspond to individual microarray probes representing genes in the titer QTL region. Black bars indicate probes for Muc4. Grey bars indicate probes for other mucins (Muc13 and Muc20) within the QTL. Open bars represent non-mucin genes within the QTL. (C) Expression of Muc4 RNA in the CC founder lines at four DPI following either mock (open symbols) or SARS-CoV (closed symbols). Dashed lines represent the mean expression level for all founder mice. 

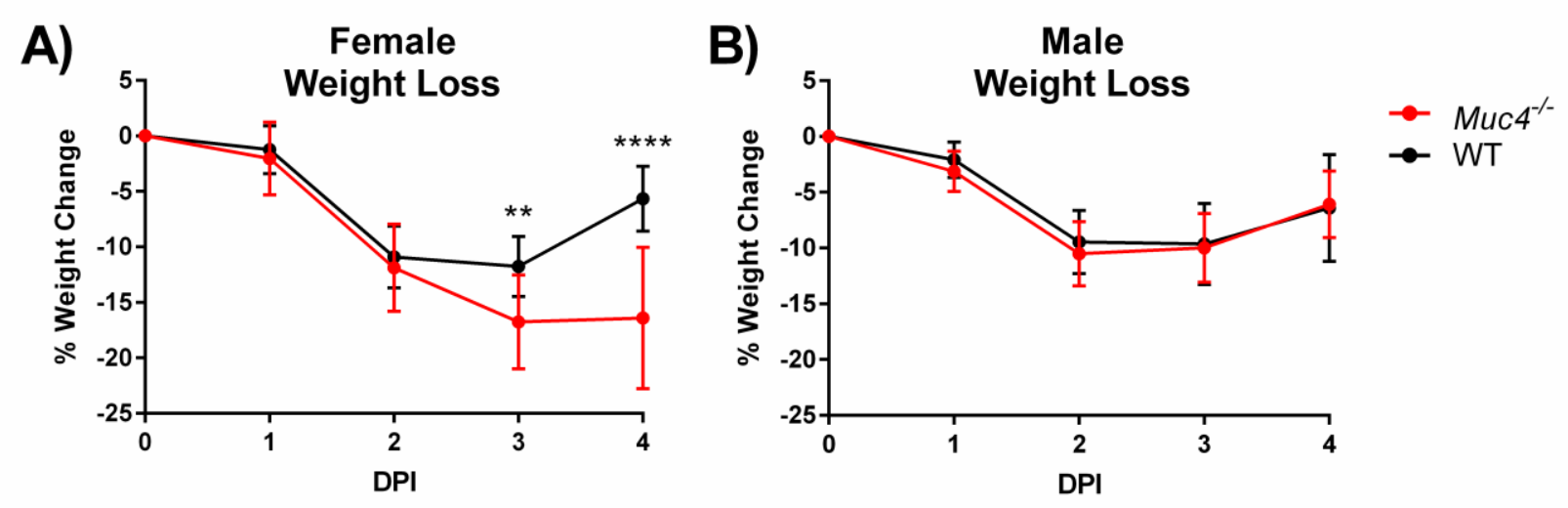

Fig. 2. Weight loss following SARS-CoV infection. Weight loss was monitored in (A) female and (B) male

607 Muc4 $^{-/}$and WT mice. Black indicates WT mice and red indicates Muc4 ${ }^{-/-}$mice. Points represent the

608 mean, and error bars represent standard deviation. Asterisks indicate statistical significance $\left(^{* *}=\right.$ 

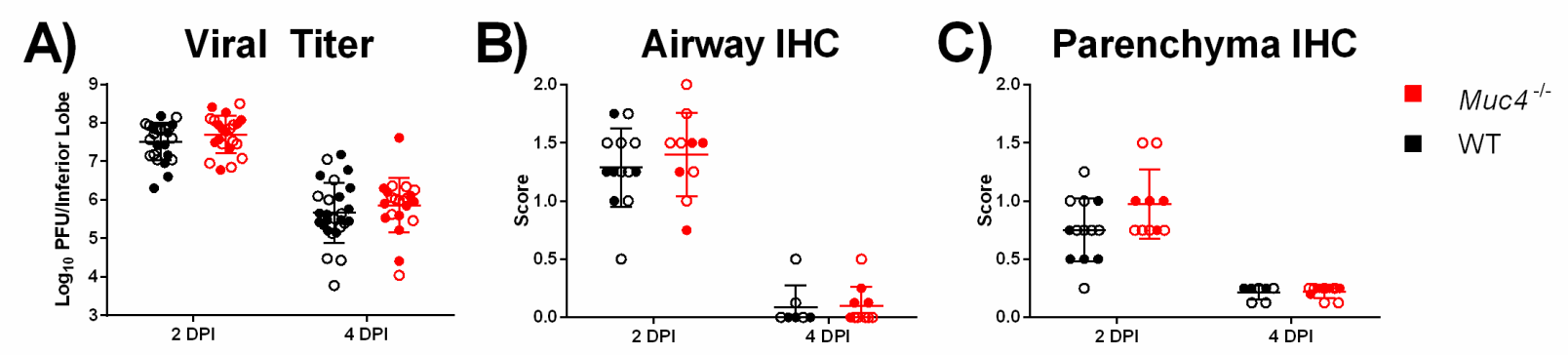

612 Fig. 3. Viral titer and tropism following SARS-CoV infection. (A) viral titer in the inferior lobes of SARS-

613 CoV infected mice at two DPI and four DPI was measured via plaque assay. SARS-CoV tropism in the (B)

614 airway and (C) parenchyma of the left lobe at two and four DPI was measured via blind scoring following

615 IHC staining. Black indicates WT mice and red indicates $\mathrm{MuC4}^{-/}$mice. Points represent individual mice

616 (close = female, open = male), the midline represents the mean, and error bars represent standard

617 deviation. No comparisons of WT versus $\mathrm{Muc4}^{-/-}$mice achieved statistical significance after correction

618 for multiple comparisons ( $q \geq 0.05$ ) 

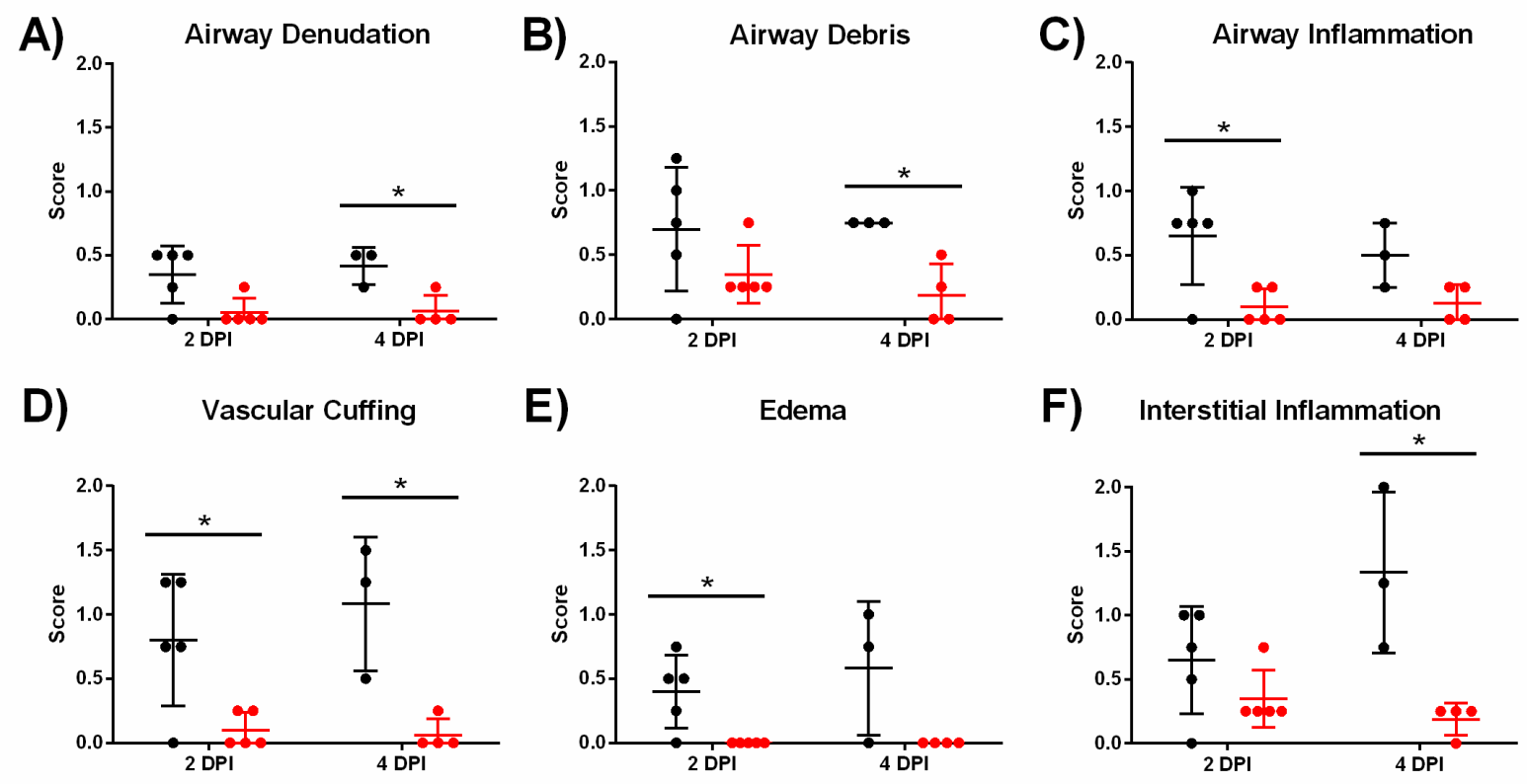

E)

Edema

F)
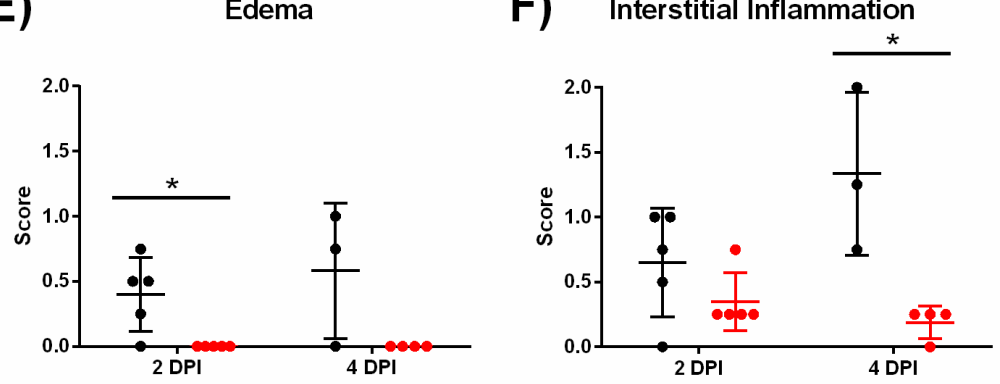

G)

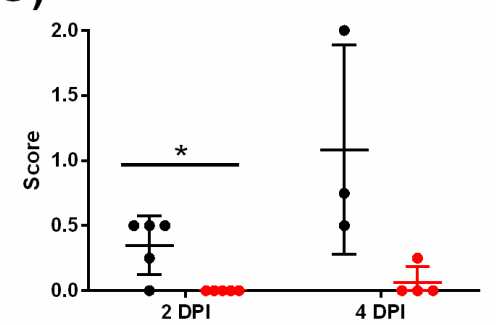

H)

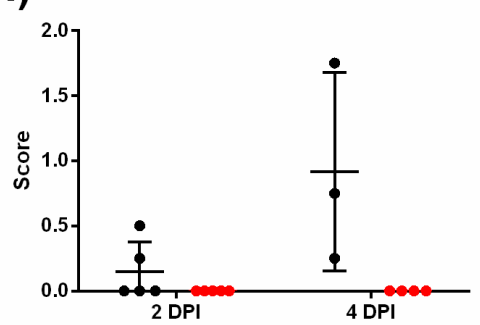

I)

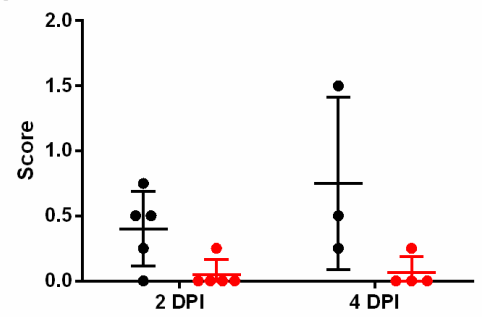

621 Fig. 4. Female WT and Muc4\% mice were infected with SARS-CoV, and their left lung lobes were 622 harvested at either two or four DPI for histopathological analysis following H\&E staining. (A) Airway denudation, (B) Airway debris, (C) Airway inflammation, (D) Vascular Cuffing, (E) Edema, (F) Interstitial Inflammation, (G) Airspace Inflammation, (H) Exudate, and (I) Eosinophilia were all scored. Black indicates WT mice and red indicates $\mathrm{Muc4}^{-{ }^{--}}$mice. Points represent individual mice, the midline represents the mean, and error bars represent the standard deviation. Asterisks indicate statistical significance $(*=q<0.05)$. 

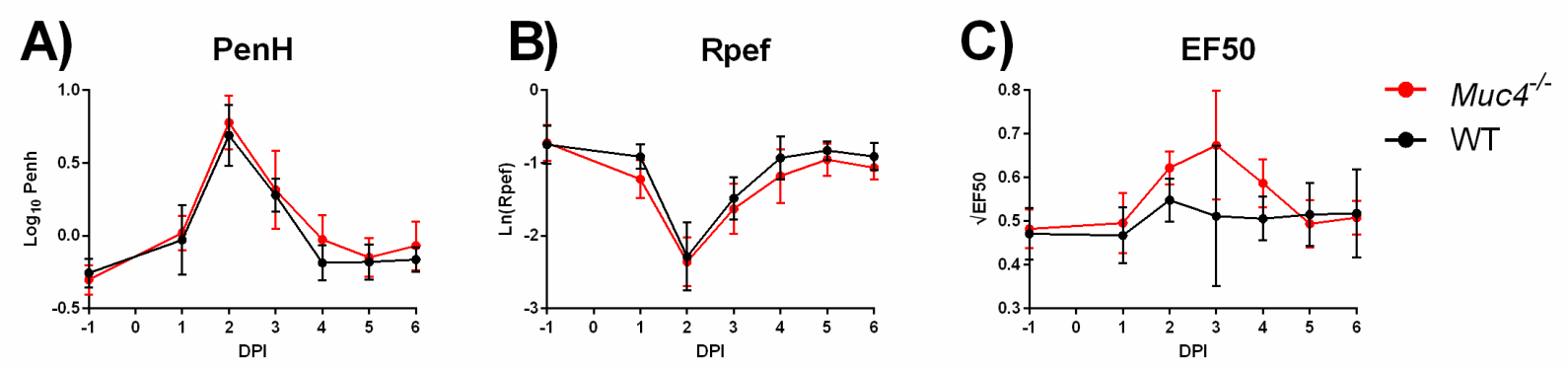

630

631 Fig. 5. Pulmonary function as measured by normalized (A) PenH, (B) Rpef, and (C) EF50 readings was

632 recorded in SARS-CoV-infected female mice. Black indicates WT mice and red indicates Muc4 ${ }^{-{ }^{-}}$mice.

633 Points represent the mean and error bars represent the standard deviation. Strain-based differences

634 did not achieve statistical significance after correction for multiple comparisons ( $q \geq 0.05$ ).

635 


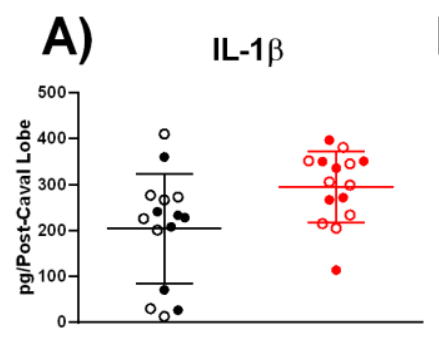

B)
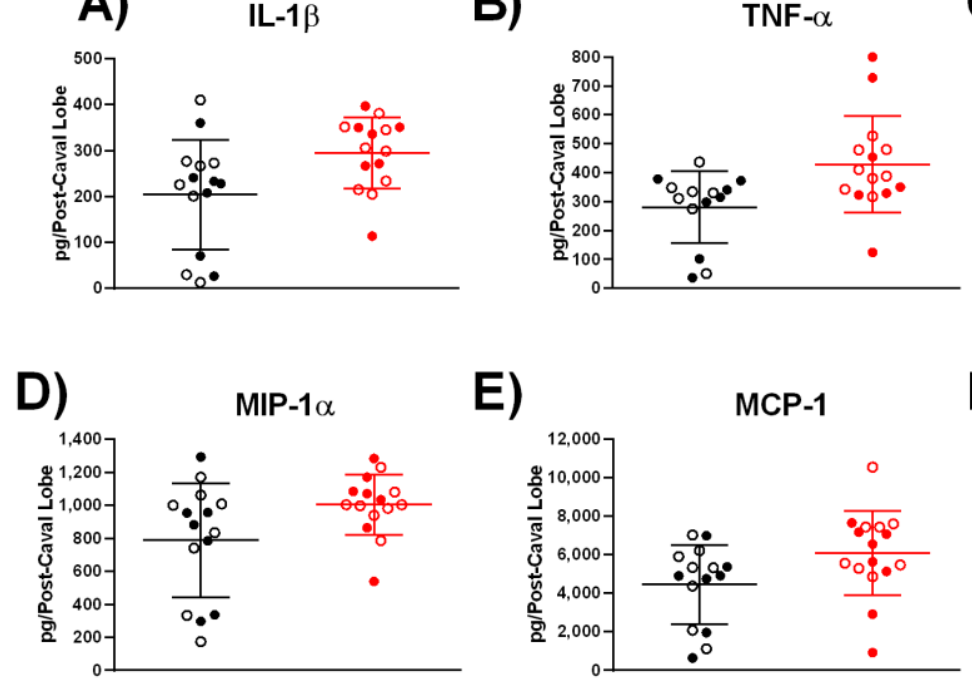

E)

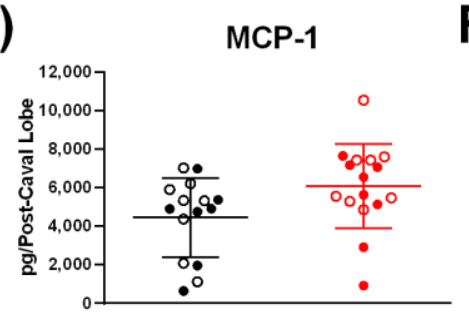

C)

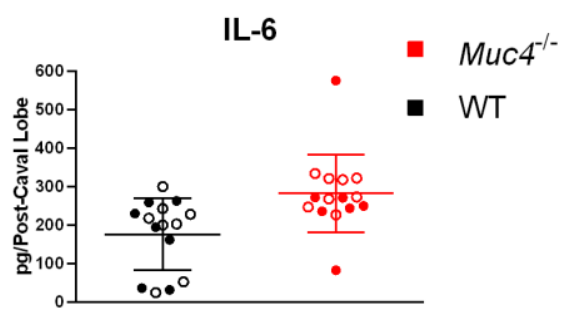

F)

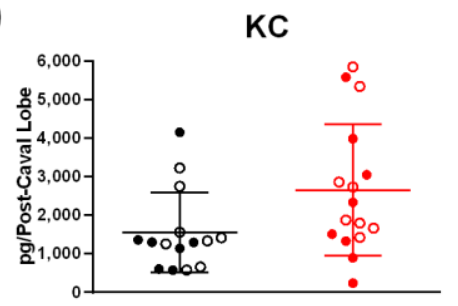

637 Fig. 6. Cytokine levels, including (A) IL-1 $\beta$, (B) TNF- $\alpha$, (C) IL-6, (D) MIP-1 $\alpha$, (E) MCP-1, and (F) KC, at 2 DPI 638 in post-caval lobes of SARS-CoV-challenged mice were measured using a BioPlex assay. Black indicates 639 WT mice and red indicates $\mathrm{Muc4}^{-/}$mice. Points represent individual mice (close $=$female, open $=$male), 640 the midline represents the mean, and error bars represent standard deviation. Strain-based differences 641 did not achieve statistical significance after correction for multiple comparisons ( $q \geq 0.05)$. 

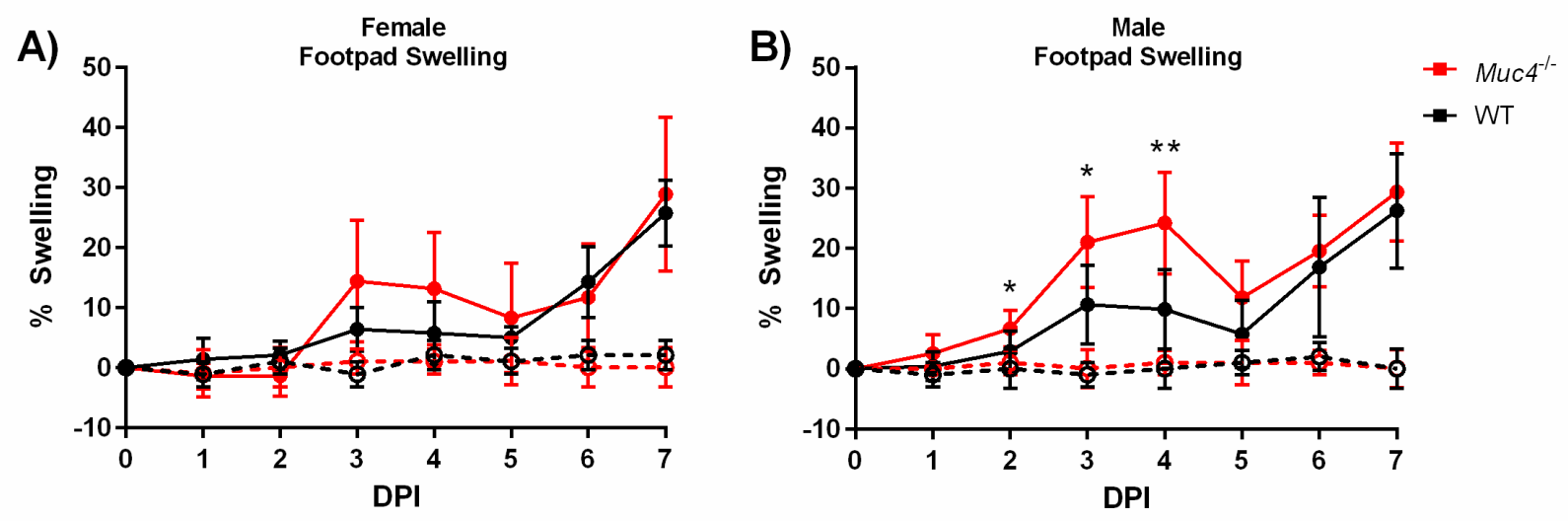

644 Fig. 7. Footpad swelling in (A) female and (B) male mice that have been either mock-infected or infected 645 with CHIKV. Black indicates WT mice and red indicates Muc4 ${ }^{-/}$mice. Dashed lines with open symbols 646 indicate mock infection, and solid lines with solid symbols indicate CHIKV infection. Points represent the 647 mean and error bars represent the standard deviation. Asterisks indicate statistical significance $(*=$ $648 \mathrm{q}<0.05, * *=\mathrm{q}<0.01)$. 